\title{
Astaxanthin Inhibits Helicobacter pylori-induced Inflammatory and Oncogenic Responses in Gastric Mucosal Tissues of Mice
}

\author{
Hwana Han, Joo Weon Lim, Hyeyoung Kim \\ Department of Food and Nutrition, BK21 FOUR, College of Human Ecology, Yonsei University, Seoul, Korea
}

\begin{abstract}
Helicobacter pylori is recognized as a risk factor for gastric carcinogenesis. The chronic exposure of gastric epithelium to $H$. pylori induces a prolonged inflammatory state that may progress to gastric cancer. Astaxanthin, a pinkish antioxidant carotenoid, abundant in marine organisms, is known for its protective effect against inflammation and multiple types of cancer. The purpose of this study was to examine the effect of astaxanthin on $\mathrm{H}$. pylori-induced oxidative injury, inflammation, and oncogene expression in gastric mucosal tissues of the infected mice. Mice were inoculated using oral gavage with $H$. pylori suspension $\left(10^{8}\right.$ colony forming unit of $H$. pylori/ $0.1 \mathrm{~mL}$ ) for three days, after which they were fed astaxanthin-supplemented diet $(5 \mathrm{mg} / \mathrm{kg}$ body weight/day for seven weeks). The effects of astaxanthin on H. pylori-induced increase in lipid peroxide (LPO) production, myeloperoxidase (MPO) activity, expression of the inflammatory cytokine IFN- $\gamma$ and oncogenes (c-myc and cyclin D1), and the accompanying histologic changes in gastric mucosal tissues were evaluated. H. pylori infection increased the level of LPO, MPO activity, and the expression of IFN- $\gamma$, c-myc, and cyclin D1 in gastric mucosal tissues of mice. H. pylori infection induced neutrophil infiltration and hyperplasia of gastric mucosa. Astaxanthin supplementation attenuated these effects. In conclusion, consumption of astaxanthin-rich foods may prevent $H$. pylori-associated oxidative damage and inflammatory and oncogenic responses in gastric mucosal tissues.
\end{abstract}

Key Words Astaxanthin, Helicobacter pylori, Gastric mucosa, Inflammation, Oncogene

\section{INTRODUCTION}

Helicobacter pylori (H. pylori) is widely recognized as a major risk factor for gastric inflammation. Moreover, the continued gastric mucosal exposure to $H$. pylori results in a chronic inflammatory state as the host tries to protect itself from the bacterium, which in turn increases the risk of gastric carcinogenesis [1]. The levels of inflammatory cytokines, such as interleukin-8 and IFN- $\gamma$, increased in $H$. pylori-infected gastric cancer patients $[2,3]$. These inflammatory mediators act as chemoattractants recruiting neutrophils to the infected site and increasing the level of reactive oxygen species (ROS) in the host's cells [4]. Indeed, increased ROS production was reported in the gastric tissues of patients infected by $\mathrm{H}$. pylori [5]. ROS are widely accepted as major pathogenic factors in $\mathrm{H}$. pylori-induced gastric carcinogenesis, as the resulting oxidative DNA damage is considered one of the significant events heralding the progression to carcinogenesis [6]. Pre- vious studies revealed that $H$. pylori infection increased the cellular ROS level by activating NADPH oxidase in human gastric epithelial cells $[7,8]$. The release of large amounts of ROS from infiltrated neutrophils by NADPH oxidase activity may contribute to the activation of redox-sensitive oncogenic signaling pathways, such as the NF-kB and the Wnt pathway [9], which are known to regulate oncogenes at the transcriptional and post-transcriptional levels. The regulated oncogenes include c-myc and cyclin D1 [10,11], which function as key elements of cancer development in humans. Overexpression of c-myc and cyclin D1 has been observed in over $40 \%$ and $22 \%$ of gastric cancer cases, respectively $[12,13]$. Moreover, several in vitro studies have demonstrated that the aberrant expression of these genes is involved in the proliferation of gastric cancer cells $[14,15]$. Therefore, the association of $H$. pylori infection with c-myc and cyclin D1 expression in gastric mucosa needs to be clarified in order to understand H. pylori-mediated gastric carcinogenesis in depth. 
Astaxanthin is the ketocarotenoid responsible for the red-orange pigmentation observed in aquatic organisms such as salmons and lobsters [16]. Astaxanthin has attracted substantial interest due to its anti-inflammatory and anti-cancer effects [17]. Our previous study has revealed that astaxanthin protects gastric epithelial cells from the harmful effects of $H$. pylori infection by attenuating the induction of ROS production and increasing the activity of antioxidant enzymes [8]. These results led us to propose the hypothesis that astaxanthin may avert $H$. pylori-associated gastric alterations including oxidative damage (increase in lipid peroxide [LPO] levels and myeloperoxidase [MPO] activity) and the expression of the inflammatory cytokine IFN- $\gamma$ as well as oncogenes (c-myc and cyclin D1) in gastric mucosal tissues of the infected hosts.

\section{MATERIALS AND METHODS}

\begin{abstract}
Animals
Male C57BL/6 mice (6 weeks of age), purchased from Orient Bio Inc. (Seongnam, Korea), were maintained in a controlled room in the animal facility of Yonsei University College of Medicine under the following conditions: temperature, $23.0^{\circ} \mathrm{C}$ $\pm 3.0^{\circ} \mathrm{C}$; humidity, $50 \% \pm 10 \%$; 12 -hour light/dark cycle. Animals were housed in polypropylene cages furnished with hardwood chip bedding ( 5 animals per cage) and had free access to food and water. All experimental procedures were approved by the Institutional Review Board (IRB) at Animal Ethical and Experimental Committee of Yonsei University College of Medicine, Seoul, Korea (IRB No. IACUC No. 2018-0127).
\end{abstract}

\section{Bacterial inoculation}

The $H$. pylori strain NCTC 11637 (CagA+ and VacA+) was obtained from the American Type Culture Collection (Rockville, MD, USA) and stored at $-80^{\circ} \mathrm{C}$ in $\mathrm{BBL}$ Brucella Broth (Becton, Dickinson and Company, Franklin Lakes, NJ, USA) supplemented with 10\% FBS (Gibco; Grans Island, NY, USA). Bacterial cells were grown and prepared under previously described conditions [8]. After reaching the exponential phase, bacteria were suspended in PBS at a density of $10^{9}$ colony forming unit (CFU)/mL. No specific pretreatments (such as acid inhibition or antibiotics) were used before orogastric $H$. pylori inoculation or before the animals were sacrificed. Mice were orogastrically inoculated 3 times (days 0 , 1, and 2) with $0.1 \mathrm{~mL}$ of the inoculum preparation of $H$. pylori $\left(10^{8} \mathrm{CFU}\right.$ of $H$. pylori/0.1 $\mathrm{mL}$ ) through a feeding needle. Prior to each inoculation, mice were fasted for 12 hours. Non-inoculated control mice were administered $0.1 \mathrm{~mL}$ of sterile PBS under identical conditions.

\section{Experimental protocol}

The mice were randomly assigned to the following 3 groups ( $n=15$ per group): (1) non-infected control (None) group comprising mice administered sterile PBS and fed standard chow (AIN-76A; Research Diets, New Brunswick, NJ, USA); (2) infected control $(H$. pylori control) group comprising mice inoculated with $H$. pylori and fed standard chow; (3) astaxanthin $(H$. pylori + ASX) group comprising mice infected with $H$. pylori and fed an AIN-76A diet supplemented with $0.005 \%$ astaxanthin (Sigma-Aldrich, St. Louis, MO, USA). The daily dose of astaxanthin was set at $5 \mathrm{mg} / \mathrm{kg}$ body weight, based on previous studies demonstrating that astaxanthin decreased the incidence of colonic adenocarcinoma in a mouse colitis model and hepatic cholesterol levels in mice fed a highfat diet $[18,19]$.

Mice were weighed weekly during the study period, while food intake was evaluated three times a week. Mice were killed by carbon dioxide inhalation at the end of the 7th week. Upon death, gastric mucosal tissues were collected. One half of the tissues were subjected to histological analysis. The remaining tissues were homogenized in RIPA buffer (150 mM $\mathrm{NaCl}, 1 \%$ Nonidet $\mathrm{P}-40,0.5 \%$ sodium deoxycholate, $0.1 \%$ SDS, and $25 \mathrm{mM}$ Tris $\mathrm{pH} 7.4$ ) and used for the determination of LPO abundance, MPO activity, levels of total protein (using the Bradford assay; Bio-Rad Laboratories, Hercules, CA, USA), and protein and mRNA levels of IFN- $\gamma, \mathrm{c}-\mathrm{myc}$, and cyclin D1.

\section{Assessment of LPO level and MPO activity}

For evaluating the oxidative damage, the level of LPO was assessed by measuring the gastric mucosal concentration of malondialdehyde according to the method of Ohkawa et al. [20]. Results were expressed as $\mathrm{nmol} / \mathrm{mg}$ protein. For the determination of the gastric mucosal accumulation of neutrophilic components, the activity of MPO, a peroxidase enzyme abundantly expressed in neutrophils, was quantified according to the modified method of Krawisz et al. [21] and expressed in $\mathrm{U} / \mathrm{mg}$ protein. One unit of MPO indicates the enzymatic activity needed to reduce $1 \mu \mathrm{mol}$ of hydrogen peroxide per minute at $25^{\circ} \mathrm{C}$.

\section{Real-time PCR analysis}

The mRNA levels of IFN- $\gamma$, c-myc, and cyclin D1 were assessed using real-time PCR. Complementary DNA (cDNA) was generated from total RNA by reverse transcription using random hexamers and MuLV reverse transcriptase (Promega; Madison, WI, USA) using the following protocol: $23^{\circ} \mathrm{C}$ for 10 minutes, $37^{\circ} \mathrm{C}$ for 60 minutes, and $95^{\circ} \mathrm{C}$ for 5 minutes. The cDNA was amplified with the specific primers and FAM$\mathrm{BHQ}$-labeled probes described in Table 1 under the following conditions: 45 cycles of denaturation at $95^{\circ} \mathrm{C}$ for 30 seconds, annealing at $55^{\circ} \mathrm{C}$ for 20 seconds, and extension at $72^{\circ} \mathrm{C}$ for 30 seconds. In the first cycle, the $95^{\circ} \mathrm{C}$ step was extended to 3 minutes. GAPDH was used as the reference gene for data normalization. 


\section{Western blot analysis}

Western blot analysis was conducted as previously described [22]. After electro-blotting, nitrocellulose membranes were probed using antibodies for c-myc (sc-40), cyclin D1 (sc8396), IFN- $\gamma$ (sc-52673), and $\beta$-actin (sc-47778; all purchased from Santa Cruz Biotechnology, Dallas, TX, USA) diluted in TBS-Tween solution containing $2 \%$ dry milk, and incubated overnight at $4^{\circ} \mathrm{C}$. After washing three times with TBS-Tween, the primary antibodies were detected using horseradish peroxidase-conjugated anti-mouse secondary antibody and visualized with the enhanced chemiluminescence detection system (Santa Cruz Biotechnology). $\beta$-Actin was used as a loading control. Results were expressed as the percentage density ratio of each protein to $\beta$-actin.

\section{Histological analysis}

Half of the stomach tissues dissected from mice were fixed in freshly prepared $10 \%$ neutral-buffered formalin, embedded in paraffin, cut into $4 \mu \mathrm{m}$ slices, stained with hematoxylin and eosin, and subjected to morphological observation under an optical microscope. To evaluate pathological changes, microscopic images $(200 \times)$ were examined by a single investiga- tor who was blind to the group assignments.

\section{Statistical analysis}

All values were expressed as means \pm SEM. One-way ANOVA was carried out to assess statistical significance, followed by Newman-Keul's post-hoc test. Differences with $P<0.05$ were considered statistically significant.

\section{RESULTS}

\section{Astaxanthin does not change body weight gain} and daily food intake in $\boldsymbol{H}$. pylori-infected mice Body weight gain in the infected control group $(H$. pylori control) tended to increase compared to the ASX group $(H$. pylori + ASX) (Fig. 1A). However, the changes in the body weight among the three groups at the end of the experiment were not significantly different. The average daily food intake did not show significant differences among the three groups (Fig. 1B).

Table 1. Mouse primers for RT-PCR

\begin{tabular}{cll}
\hline Gene & Primer & \multicolumn{1}{c}{ Sequence (5'-3') } \\
\hline GAPDH & Probe & FAM-TCATACTTCTCATGGTTCACACCCATCACG-BHQ1 \\
& Forward & TTGCTGACAATCTTGAGGGAGTT \\
& Reverse & CTGCTGATGCCCCCATGT \\
IFN- $\gamma$ & Probe & FAM-CTCACAGACCTCCAGCAT-BHQ1 \\
& Forward & TGCCATCCATGCGGAAA \\
c-myc & Reverse & AGCGGGAAGACTCCTCTTC \\
& Probe & FAM-ACCTCCGCACAGCCCACTGGT-BHQ1 \\
& Forward & AGCGACTCTGAAGAAGAGCA \\
Cyclin D1 & Reverse & CGTAGTTGTGCTGGTGAGTG \\
& Probe & FAM-TCACCATCCTTTTGCCAGTTCCTCCAG-BHQ1 \\
& Forward & TCAAGTGGCATAGATGTGGAAGAA \\
& Reverse & TGGCTCTGCAGGATTTTCATG \\
\hline
\end{tabular}

RT-PCR, real-time PCR.
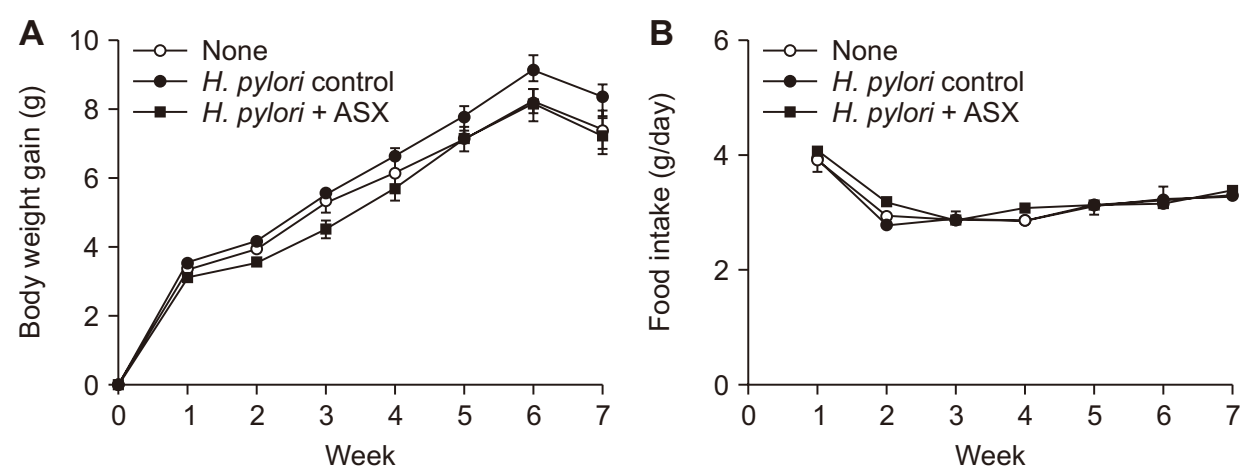

Figure 1. Effects of astaxanthin on body weight gain and daily food intake of mice infected with $H$. pylori. (A) Graph showing the weekly changes in body weight of each group. (B) Graph showing the average daily food intake of each group as measured three times a week. Values are presented as mean \pm SEM ( $n=15$ for each group). None, non-infected mice fed standard chow; $H$. pylori control, $H$. pylori-infected mice fed standard chow; H. pylori + ASX, H. pylori-infected mice fed chow supplemented with astaxanthin (ASX). 


\section{Astaxanthin decreases the level of LPO and MPO activity in $\boldsymbol{H}$. pylori-infected gastric mucosa}

The level of LPO reflects the oxidative stress to lipids, and, by extension, is indicative of the oxidative injury to cells. On the other hand, MPO activity is used as an index for $\mathrm{H}$. pylori-induced accumulation of neutrophils because of the abundance of this enzyme in the infected tissues. Comparing the values of the non-infected (None) and the infected control $(H$. pylori control) groups (Fig. 2) revealed that $H$. pylori infection significantly increased both LPO level and MPO activity in gastric mucosal tissues. Notably, astaxanthin supplementation attenuated the infection-induced elevation of LPO production and MPO activity in mouse gastric mucosal tissues. These results demonstrate that astaxanthin may inhibit $H$. pylori-induced oxidative stress and neutrophil influx to mouse gastric mucosal tissues.

\section{Astaxanthin suppresses the expression of IFN- $\gamma$, C-myc, and cyclin D1 in H. pylori-infected gastric mucosa}

H. pylori infection significantly increased both the mRNA and protein levels of IFN- $\gamma$, whereas astaxanthin supplementation attenuated these effects (Fig. 3). The same changes, i.e., increases in the infected controls and attenuation by astaxanthin, were observed in the two examined oncogenes, c-myc and cyclin D1 (Fig. 4). These results indicate that astaxanthin can suppress $H$. pylori-mediated gastric carcinogenesis by attenuating the expression of inflammatory mediators and oncogenes in gastric mucosa.

\section{Astaxanthin prevents $\boldsymbol{H}$. pylori-induced alterations in gastric mucosa}

The gastric mucosa of the uninfected (None) group displayed normal morphology, i.e., lack of inflammation or hyperplasia
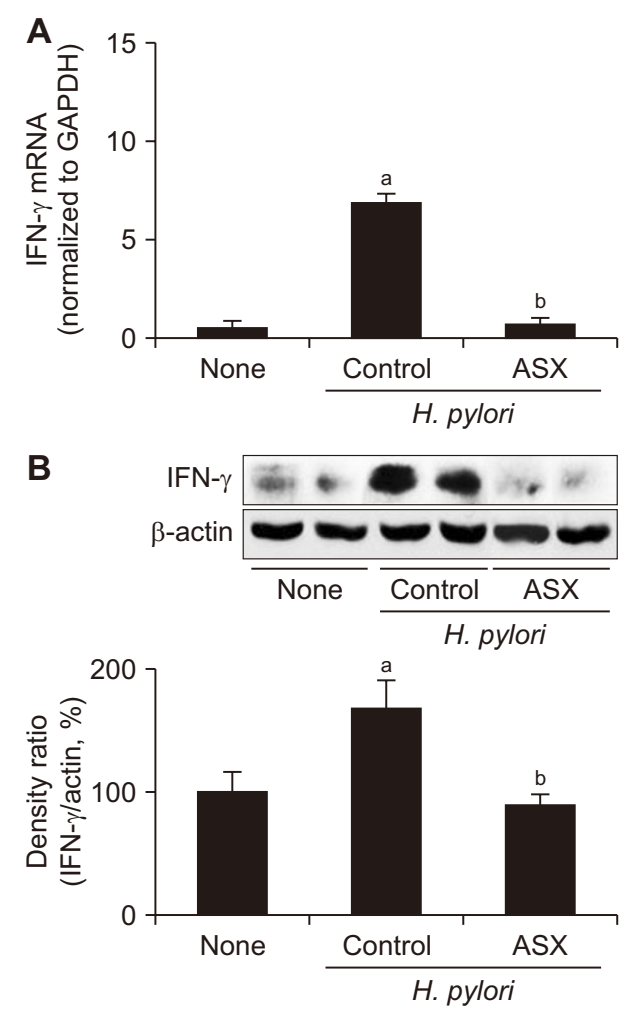

Figure 3. Effect of astaxanthin on the expression of IFN- $\gamma$ in the gastric mucosal tissues of $\boldsymbol{H}$. pylori-infected mice. (A) IFN- $\gamma$ mRNA levels in the gastric mucosal tissues were assessed by real-time PCR. GAPDH mRNA was used to normalize the results. (B) Upper: Western blot analysis of IFN- $\gamma$. Lower: graph showing the levels of each protein as a density ratio relative to the density of the loading control ( $\beta$-actin). The density ratio of the non-infected control (None) group was set as $100 \%$. None, non-infected mice fed standard chow; Control $(H$. pylori control), H. pylori-infected mice fed standard chow; ASX (H. pylori + ASX), H. pylori-infected mice fed chow supplemented with astaxanthin (ASX). ${ }^{a} P<0.05$ vs. non-infected controls (None), ${ }^{b} P<0.05$ vs. infected controls (H. pylori control).
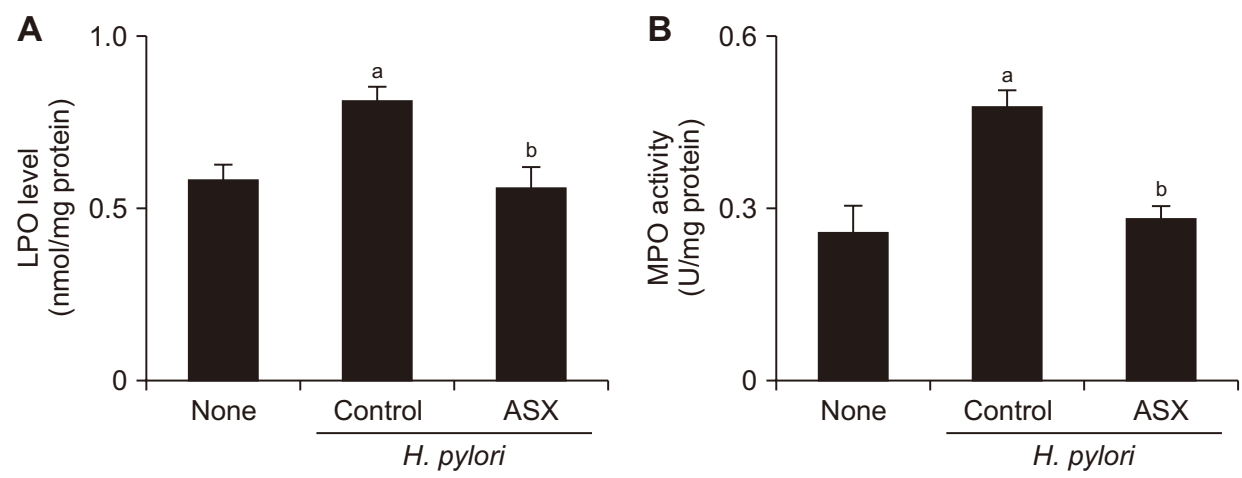

Figure 2. Effect of astaxanthin on lipid peroxide (LPO) level and myeloperoxidase (MPO) activity in the gastric mucosal tissues of $H$. pyloriinfected mice. (A) Graph showing the level of LPO in each of the three groups, expressed as nmol/mg of protein. (B) Graph showing MPO activity in each of the three groups, expressed as units/mg protein. Values are presented as mean \pm SEM ( $n=5$ for each group). None, non-infected mice fed standard chow; Control (H. pylori control), H. pylori-infected mice fed standard chow; ASX (H. pylori + ASX), H. pylori-infected mice fed chow supplemented with astaxanthin (ASX). ${ }^{a} P<0.05$ vs. None, ${ }^{b} P<0.05$ vs. infected controls $(H$. pylori control). 
Han et al.
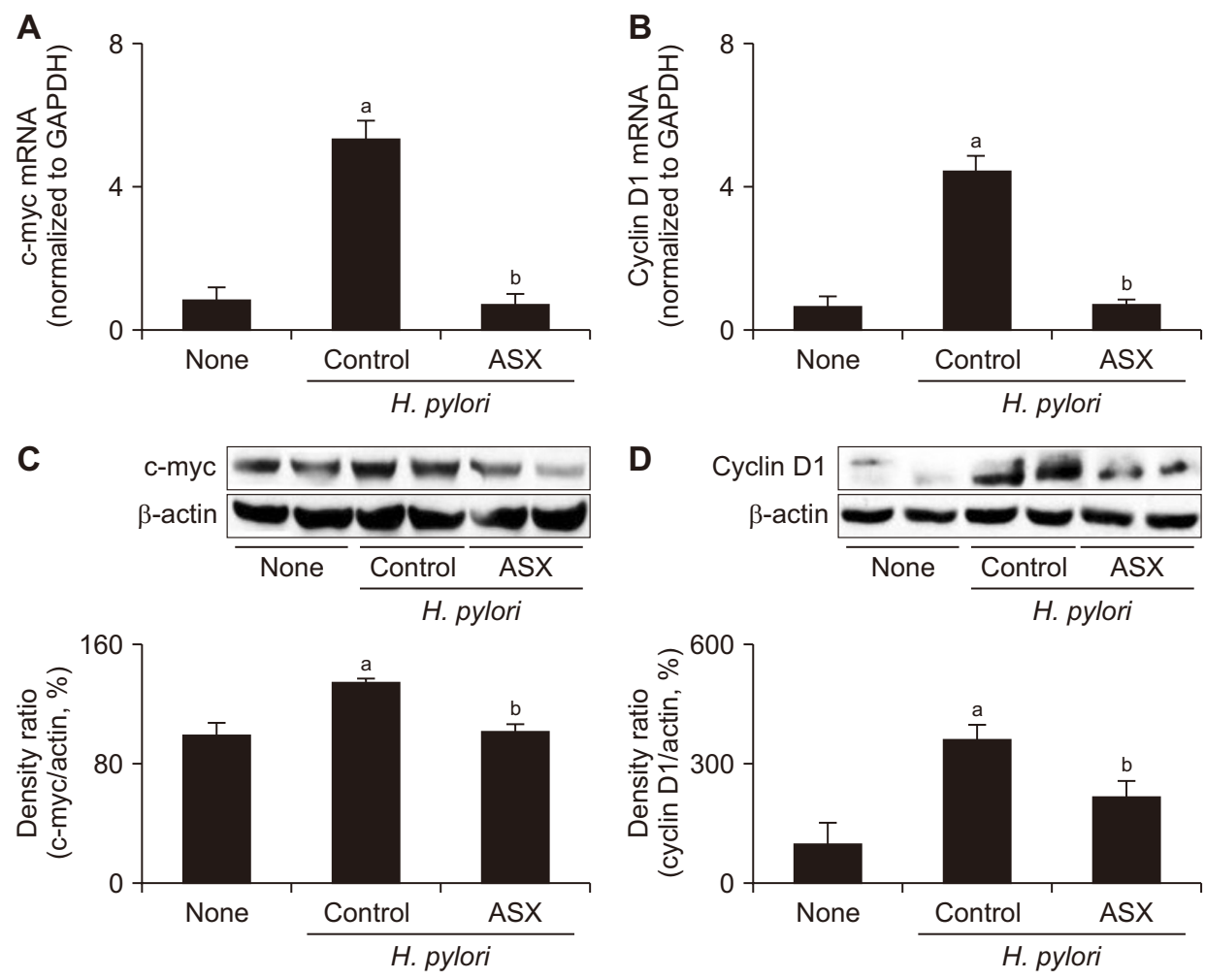

Figure 4. Effect of astaxanthin on the expression of c-myc and cyclin D1 in the gastric mucosal tissues of $\boldsymbol{H}$. pylori-infected mice. (A, B) c-myc and cyclin D1 mRNA levels in the gastric mucosal tissues as assessed by RT-PCR; GAPDH mRNA was used to normalize the results. (C, D) Upper: Western blot analysis of c-myc and cyclin D1. Lower: graph showing the levels of each protein as a density ratio relative to the density of the loading control ( $\beta$-actin). The density ratio of the None group was set as $100 \%$. None, non-infected mice fed standard chow; Control $(H$. pylori control), $H$. pylori-infected mice fed standard chow; ASX (H. pylori + ASX), H. pylori-infected mice fed chow supplemented with astaxanthin (ASX). ${ }^{a} P<0.05$ vs. non-infected controls (None), ${ }^{b} P<0.05$ vs. infected controls ( $H$. pylori control).

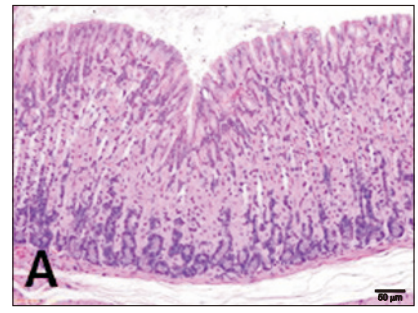

None

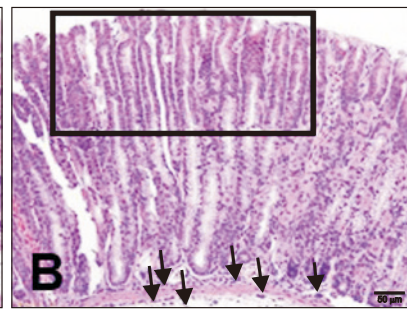

H. pylori control

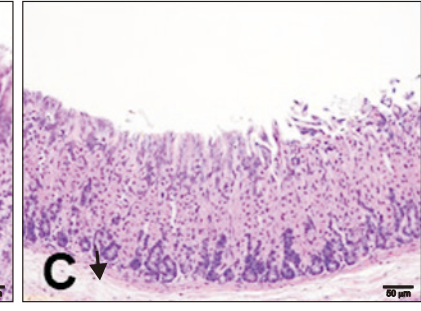

H. pylori + ASX

Figure 5. Effect of astaxanthin on $\boldsymbol{H}$. pylori-induced gastric mucosal damage. (A) Normal gastric tissue from None group. (B) Abnormal gastric tissue from $H$. pylori control groups. Focal hyperplastic glands (square) and infiltration of neutrophils (arrows) are observed. (C) Gastric mucosal tissues from H. pylori + ASX group. Both the presence of focal hyperplastic glands and the infiltration by neutrophils are less profound than in (B). All images are hematoxylin and eosin-stained gastric mucosal sections viewed under an optical microscope at $200 \times$. The bar represents a length of 50 $\mu \mathrm{m}$. None, non-infected mice fed standard chow; H. pylori control, H. pylori-infected mice fed standard chow; H. pylori + ASX, H. pylori-infected mice fed chow supplemented with astaxanthin (ASX).

(Fig. 5A). In contrast, the infected control (H. pylori control) group had mild inflammation and hyperplasia, as indicated by the presence of focal hyperplastic glands and the infiltration of neutrophils in the gastric mucosa (Fig. 5B). Infected mice fed an astaxanthin-supplemented diet (H. pylori + ASX) exhibited reduced neutrophil infiltration and hyperplasia compared to those of the infected control group (Fig. 5C). These results suggest that astaxanthin supplementation might exert a preventive effect against $H$. pylori-induced gastric alterations.

\section{DISCUSSION}

Oxidative stress in the gastric mucosa resulting from $\mathrm{H}$. pylori infection has a crucial role in gastric carcinogenesis. H. pylori 
infection is highly correlated with increased oxidative damage to the gastric mucosa [1]. In particular, the elevated production of ROS enhances the generation of LPO, as they react with polyunsaturated fatty acids in the cellular membrane and promote the oxidative degradation of the lipids [23]. Therefore, the increased LPO level observed in this study after the inoculation with $H$. pylori may be attributed to infection-induced oxidative damage to gastric mucosa cells. Since astaxanthin treatment reversed this effect, we conclude that its antioxidative activity might protect gastric tissues from the oxidative damage induced by $H$. pylori infection. Our results concur with those of previous studies in which the oral administration of astaxanthin was shown to prevent the elevation of the LPO level in the gastric tissues in a mouse model of gastric ulceration [24,25].

$H$. pylori-induced inflammation is characterized by the persistent infiltration of neutrophils in gastric mucosa, which contributes to the pathologies of gastric disorders, particularly by releasing inflammatory mediators and ROS [26]. This was confirmed in our study, as MPO activity, an indicator of neutrophil influx in tissues, was elevated by $H$. pylori infection. Importantly, this increase was mitigated by astaxanthin treatment.

Increased expression of IFN- $\gamma$ after $H$. pylori infection has been observed in the stomach tissues of Mongolian gerbils [27] and humans [3]. H. pylori is known to stimulate the production of IFN- $\gamma$ from peripheral blood mononuclear cells and lymphocytes in gastric tissue [28]. A role for IFN- $\gamma$ in $\mathrm{H}$. pylori-induced gastric inflammation is supported by the finding that infected IFN- $\gamma^{-/-}$mice develop less severe gastritis compared with their wild-type counterparts [29]. In the current study, H. pylori infection increased the mRNA and protein levels of IFN- $\gamma$ in mouse gastric mucosa, whereas astaxanthin intake attenuated this increase. These findings are consistent with the previous observation that the dietary intake of astaxanthin can reduce the release of IFN- $\gamma$ in splenocytes extracted from $H$. pylori-infected mice [30], and suggest that astaxanthin supplementation might alleviate the gastric inflammation by reducing $H$. pylori-induced IFN- $\gamma$ expression.

Several studies have shown that $H$. pylori infection increases the expression of c-myc and cyclin D1 and induces hyperproliferation in gastric epithelial AGS cells [14,31]. Since the transcription factor c-myc suppresses the cell cycle arrest and enhances cell proliferation, the deregulation of its expression is a pivotal event in the pathological process leading to cancer [32]. On the other hand, cyclin D1 plays a major role in cell-cycle control as it allows the cycle to progress from the $\mathrm{G} 1$ to the $\mathrm{S}$ phase. Abnormal cyclin D1 expression is known to participate in cancer development and progression by increasing the rate of cellular proliferation [33]. Our data show that astaxanthin supplementation attenuates the increases in the mRNA and protein levels of c-myc and cyclin D1 in mouse gastric tissues that would otherwise result from $H$. pylori infection. These results are in line with previous findings illustrating that astaxanthin decreases the expression of both proteins and inhibits the proliferation of human gastric cancer and colon cancer cells [34,35].

We have previously demonstrated that activation of $N F-\kappa B$ and AP-1 mediates hyperproliferation by inducing $\beta$-catenin and c-myc in $H$. pylori-infected gastric epithelial cells [14]. Therefore, $N F-\kappa B$ and $\beta$-catenin signaling may mediate hyper-proliefearation via induction of c-myc and cyclins. $H$. pylori infection increased expression of c-myc and cyclin D1 through activation of $\mathrm{NF}-\kappa \mathrm{B}[14,36]$. We also showed that astaxanthin inhibited $H$. pylori-induced NF- $\mathrm{KB}$ activation in gastric epithelial cells [8]. The antioxidanr $\beta$-carotene inhibited $H$. pylori-induced cell proliferation and the expression of c-myc and cyclin $E$ by reducing the levels of $\beta$-catenin and phosphorylated glycogen synthase kinase $3 \beta$ [37]. Lycopene inhibited oxidative stress-mediated activation of $\mathrm{Wnt} / \beta$-catenin signaling including alteration of $\mathrm{Wnt} / \beta$-catenin multiprotein complex molecules and attenuated hyper-proliferation in gastric epithelial cells [38]. These studies suggest that astaxanthin supplement may suppress $H$. pylori-induced expression of c-myc and cyclin D1 through inhibition of NF- $\mathrm{NB}$ activation and $\mathrm{Wnt} / \beta$-catenin signaling in gastric mucosal tissues.

Jin et al. [39] and Luo et al. [40] demonstrated that 6- to 7-week-treatment of $H$. pylori induced erosions and infiltration of inflammatory cells, and hyperplasia in gastric mucosal tissues of mice. Our results showed that 7-week-treatment of $H$. pylori caused inflammation and hyperplasia of gastric tissues of the infected mice.

In conclusion, astaxanthin may suppress oxidative gastric tissue damage and the expression of the inflammatory cytokine, IFN- $\gamma$, and the oncogenes, c-myc and cyclin D1, in $H$. pylori-infected gastric mucosal tissues. These results suggest that astaxanthin supplementation might have a preventive effect against $H$. pylori-associated gastric carcinogenesis.

\section{ACKNOWLEDGMENTS}

This study was supported financially by a grant from the National Research Foundation (NRF) of Korea, which is funded by the Korean Government (NRF-2018R1A2B2005575). Authors are grateful to Professor Joo Young Kim (Dept. Of Pharmacology, Yonsei University College of Medicine, Seoul, Republic of Korea) for her kind advice and technical assistance in animal experimentation.

\section{CONFLICTS OF INTEREST}

No potential conflicts of interest were disclosed.

\section{ORCID}

Hwana Han, https://orcid.org/0000-0003-0705-125X

Joo Weon Lim, https://orcid.org/0000-0001-7483-3820

Hyeyoung Kim, https://orcid.org/0000-0002-7019-917X 
Han et al.

\section{REFERENCES}

1. Butcher LD, den Hartog G, Ernst PB, Crowe SE. Oxidative stress resulting from Helicobacter pylori infection contributes to gastric carcinogenesis. Cell Mol Gastroenterol Hepatol 2017;3:316-22.

2. Bartchewsky W Jr, Martini MR, Masiero M, Squassoni AC, Alvarez MC, Ladeira MS, et al. Effect of Helicobacter pylori infection on IL-8, IL-1beta and COX-2 expression in patients with chronic gastritis and gastric cancer. Scand J Gastroenterol 2009;44:153-61.

3. Abdollahi H, Shams S, Zahedi MJ, Darvish Moghadam S, Hayatbakhsh MM, Jafarzadeh A. IL-10, TNF- $\alpha$ and IFN- $\gamma$ levels in serum and stomach mucosa of Helicobacter pylori-infected patients. Iran J Allergy Asthma Immunol 2011;10:267-71.

4. Crabtree JE, Farmery SM. Helicobacter pylori and gastric mucosal cytokines: evidence that CagA-positive strains are more virulent. Lab Invest 1995;73:742-5.

5. Davies GR, Simmonds NJ, Stevens TR, Sheaff MT, Banatvala N, Laurenson IF, et al. Helicobacter pylori stimulates antral mucosal reactive oxygen metabolite production in vivo. Gut 1994;35:17985.

6. Farinati F, Cardin R, Degan P, Rugge M, Mario FD, Bonvicini $P$, et al. Oxidative DNA damage accumulation in gastric carcinogenesis. Gut 1998;42:351-6.

7. Byun E, Lim JW, Kim JM, Kim H. $\alpha$-Lipoic acid inhibits Helicobacter pylori-induced oncogene expression and hyperproliferation by suppressing the activation of NADPH oxidase in gastric epithelial cells. Mediators Inflamm 2014;2014:380830.

8. Kim SH, Lim JW, Kim H. Astaxanthin inhibits mitochondrial dysfunction and interleukin-8 expression in Helicobacter pyloriinfected gastric epithelial cells. Nutrients 2018;10:1320.

9. Korswagen $\mathrm{HC}$. Regulation of the $\mathrm{Wnt} /$ beta-catenin pathway by redox signaling. Dev Cell 2006;10:687-8.

10. Hinz M, Krappmann D, Eichten A, Heder A, Scheidereit C, Strauss M. NF-kappaB function in growth control: regulation of cyclin D1 expression and G0/G1-to-S-phase transition. Mol Cell Biol 1999;19:2690-8.

11. Tetsu O, McCormick F. Beta-catenin regulates expression of cyclin D1 in colon carcinoma cells. Nature 1999;398:422-6.

12. Calcagno DQ, Leal MF, Assumpcao PP, Smith MA, Burbano RR. MYC and gastric adenocarcinoma carcinogenesis. World J Gastroenterol 2008;14:5962-8.

13. Blok P, Craanen ME, van Diest PJ, Dekker W, Tytgat GN. Lack of cyclin D1 overexpression in gastric carcinogenesis. Histopathology 2000;36:151-5.

14. Byun E, Park B, Lim JW, Kim H. Activation of NF-kB and AP-1 mediates hyperproliferation by inducing $\beta$-catenin and c-myc in Helicobacter pylori-infected gastric epithelial cells. Yonsei Med J 2016;57:647-51.

15. Luo J, Yan R, He X, He J. Constitutive activation of STAT3 and cyclin D1 overexpression contribute to proliferation, migration and invasion in gastric cancer cells. Am J TransI Res 2017;9:5671-7.

16. Davinelli S, Nielsen ME, Scapagnini G. Astaxanthin in skin health, repair, and disease: a comprehensive review. Nutrients 2018;10:522.

17. Yuan JP, Peng J, Yin K, Wang JH. Potential health-promoting effects of astaxanthin: a high-value carotenoid mostly from microalgae. Mol Nutr Food Res 2011;55:150-65.

18. Nakao R, Nelson OL, Park JS, Mathison BD, Thompson PA, Chew BP. Effect of dietary astaxanthin at different stages of mammary tumor initiation in BALB/c mice. Anticancer Res 2010;30:2171-5.

19. Wang J, Liu S, Wang H, Xiao S, Li C, Li Y, et al. Xanthophyllomyces dendrorhous-derived astaxanthin regulates lipid metabolism and gut microbiota in obese mice induced by a highfat diet. Mar Drugs 2019;17:337.

20. Ohkawa H, Ohishi N, Yagi K. Assay for lipid peroxides in animal tissues by thiobarbituric acid reaction. Anal Biochem 1979;95:351-8.

21. Krawisz JE, Sharon P, Stenson WF. Quantitative assay for acute intestinal inflammation based on myeloperoxidase activity. Assessment of inflammation in rat and hamster models. Gastroenterology 1984;87:1344-50.

22. Kim A, Lim JW, Kim H, Kim H. Supplementation with Angelica keiskei inhibits expression of inflammatory mediators in the gastric mucosa of Helicobacter pylori-infected mice. Nutr Res 2016;36:488-97.

23. Kwiecien S, Jasnos K, Magierowski M, Sliwowski Z, Pajdo R, Brzozowski $B$, et al. Lipid peroxidation, reactive oxygen species and antioxidative factors in the pathogenesis of gastric mucosal lesions and mechanism of protection against oxidative stress induced gastric injury. J Physiol Pharmacol 2014;65:613-22.

24. Kim JH, Kim YS, Song GG, Park JJ, Chang HI. Protective effect of astaxanthin on naproxen-induced gastric antral ulceration in rats. Eur J Pharmacol 2005;514:53-9.

25. Wang $X$, Willén $R$, Wadström $T$. Astaxanthin-rich algal meal and vitamin $\mathrm{C}$ inhibit Helicobacter pylori infection in BALB/CA mice. Antimicrob Agents Chemother 2000;44:2452-7.

26. Robinson K, Argent RH, Atherton JC. The inflammatory and immune response to Helicobacter pylori infection. Best Pract Res Clin Gastroenterol 2007;21:237-59.

27. Crabtree JE, Court M, Aboshkiwa MA, Jeremy AH, Dixon MF, Robinson PA. Gastric mucosal cytokine and epithelial cell responses to Helicobacter pylori infection in Mongolian gerbils. J Pathol 2004;202:197-207.

28. Fan XJ, Chua A, Shahi CN, McDevitt J, Keeling PW, Kelleher D. Gastric T lymphocyte responses to Helicobacter pylori in patients with H pylori colonisation. Gut 1994;35:1379-84.

29. Smythies LE, Waites KB, Lindsey JR, Harris PR, Ghiara P, Smith $P D$. Helicobacter pylori-induced mucosal inflammation is Th1 mediated and exacerbated in IL-4, but not IFN-gamma, genedeficient mice. J Immunol 2000;165:1022-9.

30. Bennedsen M, Wang X, Willén R, Wadström T, Andersen LP. Treatment of $\mathrm{H}$. pylori infected mice with antioxidant astaxanthin reduces gastric inflammation, bacterial load and modulates cytokine release by splenocytes. Immunol Lett 1999;70:185-9.

31. Hirata Y, Maeda S, Mitsuno Y, Akanuma M, Yamaji Y, Ogura K, 
et al. Helicobacter pylori activates the cyclin D1 gene through mitogen-activated protein kinase pathway in gastric cancer cells. Infect Immun 2001;69:3965-71.

32. Vita M, Henriksson M. The Myc oncoprotein as a therapeutic target for human cancer. Semin Cancer Biol 2006;16:318-30.

33. John RR, Malathi N, Ravindran C, Anandan S. Mini review: multifaceted role played by cyclin D1 in tumor behavior. Indian J Dent Res 2017;28:187-92.

34. Palozza P, Torelli C, Boninsegna A, Simone R, Catalano A, Mele $M C$, et al. Growth-inhibitory effects of the astaxanthin-rich alga Haematococcus pluvialis in human colon cancer cells. Cancer Lett 2009;283:108-17.

35. Kim JH, Park JJ, Lee BJ, Joo MK, Chun HJ, Lee SW, et al. Astaxanthin inhibits proliferation of human gastric cancer cell lines by interrupting cell cycle progression. Gut Liver 2016;10:369-74.

36. Yang GF, Deng CS, Xiong YY, Gong LL, Wang BC, Luo J. Expression of nuclear factor-kappa $\mathrm{B}$ and target genes in gastric precancerous lesions and adenocarcinoma: association with Helicobactor pylori cagA (+) infection. World J Gastroenterol 2004;10:491-6.

37. Kim D, Lim JW, Kim H. $\beta$-carotene inhibits expression of C-Myc and Cyclin E in Helicobacter pylori-infected gastric epithelial cells. J Cancer Prev 2019;24:192-6.

38. Park B, Lim JW, Kim H. Lycopene treatment inhibits activation of Jak1/Stat3 and Wnt/ $\beta$-catenin signaling and attenuates hyperproliferation in gastric epithelial cells. Nutr Res 2019;70:7081.

39. Jin DZ, Jung HC, Kim JM, Kim JS, Song IS, Kim CY. Establishment of BALB/c mice model infected with Helicobacter pylori. Korean J Intern Med 1999;14:55-63.

40. Luo J, Song J, Zhang H, Zhang F, Liu H, Li L, et al. Melatonin mediated Foxp3-downregulation decreases cytokines production via the TLR2 and TLR4 pathways in H. pylori infected mice. Int Immunopharmacol 2018;64:116-22. 